\title{
Herbal medicines and forensic investigations
}

\author{
Roger W. Byard · Ian Musgrave
}

Published online: 9 April 2010

(C) Springer Science+Business Media, LLC 2010

Alternative medicines, including herbal therapies, are becoming increasingly popular in Western countries, with herbal treatments now being used by up to $30 \%$ of the population in the United States, with higher use in patients with HIV/AIDs and depression [1, 2]. Herbal remedies may be based on complex medical traditions spanning many hundreds of years, as in traditional Chinese and Indian systems such as Ayurveda [3]. There is no doubt that herbal therapies may have excellent clinical outcomes, and aspirin derived from tree bark or digitalis from foxglove leaves are two well-recognised examples where the active ingredient has been demonstrated to be highly effective. A problem that now occurs in Western countries is that traditional village-based activities have been expanded into the global marketplace and this may bring with it difficulties in controlling the quality, composition and purity of herbal supplies [4]. A similar problem of substitution and contamination has been found in certain illicit drugs where quality controls are lacking [5].

Although contamination with heavy metals and pesticides has been reported, the focus of this editorial is on the possible role played by herbal medicines in the mechanism of death in cases that come to medicolegal attention, and the difficulties that exist in assessing this.

Usually when an unexpected death occurs in the community investigating police officers are rigorous in

\footnotetext{
I. Musgrave

Discipline of Pharmacology, The University of Adelaide,

Adelaide, SA, Australia

R. W. Byard $(\bowtie)$

Disciplines of Anatomy and Pathology, Level 3 Medical School North Building, The University of Adelaide, Frome Road, Adelaide, SA 5005, Australia

e-mail: roger.byard@sa.gov.au; byard.roger@saugov.sa.gov.au
}

documenting prescription medications that are found at the scene. The pathologist also has a high index of suspicion for the possibility of drug overdose or interaction. Unfortunately the same process does not apply to herbal remedies that are often regarded as 'natural' products and therefore unlikely to cause problems. As well, at least $66 \%$ of people taking herbal medicines or supplements do not report this to their physician, and so there may be no documentation of their use in the medical record [6]. For this reason (in our experience) the type of herbal substances being taken by the deceased and the dosage are usually not recorded, and therefore are not investigated further. An additional problem with herbal substances is that laboratory identification of organic molecules is often extremely difficult, even when there is clear evidence of recent use [7].

One problem that arises with herbal remedies is the addition of prescription drugs to enhance their efficacy, as this may interact with prescribed medications. Examples include the addition of steroids [8] that may be contraindicated in individuals taking non-steroidal anti-inflammatory agents. The combination of herbal therapies adulterated with both steroids and anti-inflammatory drugs such as indomethacin or phenylbutazone and could initiate or exacerbate peptic ulcer disease with fatal hemorrhage. It would not be usual to suspect a possible role for herbal medicines in such a death.

Other problems arise when there is interference with the actions of prescribed medications by herbal remedies. For example, certain patients are prescribed warfarin to reduce their risk of recurrent pulmonary thromboembolism or systemic embolization from atrial fibrillation. The action of warfarin is reduced by St Johns Wort [9]. However, this would rarely be tested for in the event of these patients' deaths from thromboembolism, despite St Johns Wort 
being one of the commonest herbal medications [10] and there being a recognized high incidence of warfarin-St Johns Wort interaction [1, 9].

An additional problem arises from direct toxicity of herbal substances with reports of hepatitis, hepatic venoocclusive disease, encephalitis, hypertension and myocardial infarction [11]. Fatal hypertensive cardiac disease is a well recognised event in forensic practice but the possible role of herbal substances in the lethal event is not usually considered, at least certainly not in our practice.

This does not imply in any way that there are not significant and ongoing problems involving mortality and morbidity with prescription medications. However, adverse events are much better recognized with prescription drugs compared to herbal medicines, and protocols are in place for the evaluation of, and action on, prescription medicine events [12]. For example, routine toxicology for common prescription and non-prescription drugs is performed on body fluids and tissues in any forensic case where there is a suggestion of drug involvement. However, toxicological screening for herbal remedies is usually not performed during this process.

It appears, therefore, that we do not have a clear understanding of the possible role that herbal medicines may have in contributing to adverse events in the population of individuals who present for medicolegal investigation of the cause of death. Some questions worth considering are:

- Are herbal therapies involved in lethal outcomes in forensic practice?

- If this is the case, how common is this problem? and

- How is this best investigated?

A final question would be whether it is time to develop a discipline of forensic herbal toxicology to resolve these queries, particularly given the increasing use of herbal substances in Western communities?

\section{References}

1. Brazier NC, Levine MAH. Drug-herb interaction among commonly used conventional medicines: a compendium for health care professionals. Am J Ther. 2003;10:163-9.

2. Burg MA, Uphold CR, Findley K, Reid K. Complementary and alternative medicine use among HIV-infected patients attending three outpatient clinics in the Southeastern United States. Int J STD AIDS. 2005;16:112-6.

3. Byard RW. The potential forensic significance of traditional herbal medicines. J Forensic Sci. 2010;55:89-92.

4. Ernst E. Toxic heavy metals and undeclared drugs in Asian herbal medicines. Trends Pharmacol Sci. 2002;23:136-9.

5. Byard RW, Gilbert J, James R, Lokan RJ. Amphetamine derivative fatalities in South Australia-is "Ecstasy" the culprit? Am J Forensic Med Pathol. 1998;19:261-5.

6. Wang KennedyJ, Wu CH CC. Patient disclosure about herb and supplement use among adults in the US. Evid Based Complement Alternat Med. 2008;5:451-6.

7. Kostakis C, Byard RW. Sudden death associated with intravenous injection of toad extract. Forensic Sci Int. 2009;188:e1-5.

8. Huang WF, Wen K-C, Hsiao M-L. Adulteration by synthetic therapeutic substances of traditional Chinese medicines in Taiwan. J Clin Pharmacol. 1997;37:344-50.

9. Izzo AA, Ernst E. Interactions between herbal medicines and prescribed drugs. Drugs. 2009;69:1777-98.

10. Barnes PM, Powell-Griner E, McFann K, Nahin RL. Complementary and alternative medicine use among adults: United States, 2002. Adv Data. 2004;27:1-19.

11. Ernst E. Serious adverse effects of unconventional therapies for children and adolescents: a systematic review of recent evidence. Eur J Pediatr. 2003;162:72-80.

12. Ibrahim JE, Ranson DL, O'Brien A, Charles A, Young C. Forensic investigation of medical treatment related deaths. Leg Med. 2009;11:S71-5. 